Leser der MMW können sich ab sofort mit allen Fragen zur Abrechnung und Praxisführung an unseren Experten Helmut Walbert, Würzburg, wenden. Sie erreichen ihn jeden Donnerstag von 13 bis 15 Uhr unter der kostenlosen Rufnummer (0800) 2379830.

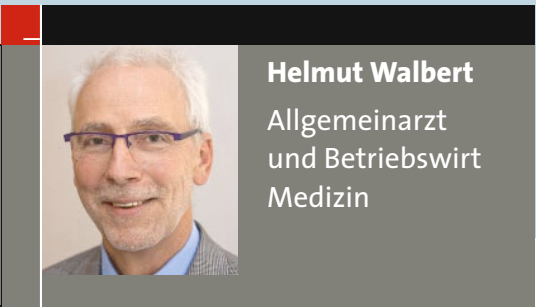

\title{
Was soll ich meinen Patienten raten?
}

Frage von Dr. med. R.M. Hausarzt-Internist, Köln

Patienten kommen in meine Sprechstunde und fragen, ob die angekündigten $\mathrm{Zu}$ satzbeiträge ihrer Krankenkassen rechtens sind und was sie tun können. Wie soll ich das Problem angehen?

Antwort : In erster Linie ist eine Basisinformation über die gesetzlichen Grundlagen wichtig. Zum Zweiten kann diese Gelegenheit auch berufspolitisch genutzt werden, einen Patienten in eine für uns Ärzte vorteilhafte Krankenkasse zu lotsen. Dies ergibt sich insbesondere in Bundesländern, in denen IV-Verträge durch den HausarztVerband oder die KV abgeschlossen wurden, die für Arzt und Patient Vorteile bieten. Als Beispiel sei der in Bayern zwischen der AOK Bayern und dem Bayerischen Hausärzteverband geschlossene Vertrag erwähnt. Hier gewinnen alle, offensichtlich auch die AOK Bayern, die zugesichert hat, dass sie 2010 den Beitragssatz stabil halten wird.

\section{Kündigungsrecht und Sonder- kündigungsrecht in der GKV}

Sowohl versicherungspflichtige als auch freiwillig versicherte Personen können die Mitgliedschaft zum Ende des übernächsten Monats kündigen. Voraussetzung ist,

\section{Kündigungsablauf:}

Kündigung alte Kasse: 26. Februar

Ende Versicherung

alte Kasse

30. April

Neue Versicherung dass die Mitgliedschaft zum Zeitpunkt der Kündigung 18 Monate bestanden hat. Hat der Patient bei oder über seine Kasse einen Wahltarif für Zusatzleistungen abgeschlossen, ist er für drei Jahre an die Kasse gebunden.

Nach erfolgtem Kassenwechsel ist bei Standardtarifen erneut die 18-monatige Mindestmitgliedschaft zu beachten.

Doch auch hier gibt es zwei Ausnahmen: Übertritt eines freiwillig versicherten Mitgliedes in eine Privatkasse oder wenn die Voraussetzungen für eine Familienversicherung gegeben sind.

Im Augenblick spielt aber das Sonderkündigungsrecht die große Rolle: Wenn eine Krankenkasse einen Zusatzbeitrag erhebt oder den erhobenen Zusatzbeitrag nochmals erhöht, spielt die 18 -Monate-Frist keine Rolle.

\section{Wird keine neue Kasse gewählt,} bleibt die alte im Amt

Versicherte, die den Zusatzbeitrag nicht zahlen wollen, können von ihrem Sonderkündigungsrecht Gebrauch machen. Erfährt ein Versicherter im Februar, dass seine Kasse einen Zusatzbeitrag erhebt, und kündigt noch im selben Monat, kann er seine Kasse Ende April verlassen. Die angekündigten Zusatzbeiträge muss er nicht zahlen, sondern nur die normalen Beiträge.

Zur Kündigung reicht ein einfaches Schreiben, auch per Fax oder E-Mail. Innerhalb von 14 Tagen muss die Krankenkasse eine Bestätigung schicken.

Mit dieser Bestätigung geht der Versicherte zur Krankenkasse seiner Wahl. In Bayern beispielsweise zur AOK, wenn er auch einem Hausarztvertrag beitreten will. Die neue Krankenkasse muss den Aufnahmewunsch ohne wenn und aber akzeptieren. Ob gesund, krank oder schwer krank spielt keine Rolle. Der bisherigen Krankenkasse muss dann noch die Mitgliedsbescheinigung der neuen Krankenkasse zugesandt werden. Erst dann ist der Wechsel wirksam. Diese Regelung schützt den Versicherten: Sollte er zum Ablauf der Kündigung noch keine neue Krankenkasse gewählt haben, bleibt die alte Krankenkasse in Amt und Pflichten. Der Patient ist also immer versichert.

\section{Internetadressen zum Thema} Zusatzbeiträge

Liste aller Krankenkassen mit Zusatzbeiträgen:

http://www.1a-krankenversicherung.org/zusatzbeitraege/liste2010.html

Allgemeine umfassende Informationen: http://www. spiegel.de/wirtschaft/unternehmen/o,1518,674302,00.html

Service für Patienten: vorformuliertes Kündigungsschreiben an die Krankenkassen zum kostenlosen Download:

http://www.walbert-helmut.de 